\title{
Host Plants of Pyrenochaeta terrestris the Causal Agent of Pink Root Rot Disease on Onion Allium cepa $\mathrm{L}$.
}

\author{
Mawahib Ahmed Elsiddig ${ }^{* 1}$ and Siddig Mohamed El Hassan ${ }^{2}$ \\ ${ }^{1}$ Department, plant protection, College of Agricultural Studies Sudan University of Science and Technology, \\ Shambat, Khartoum State,Sudan \\ ${ }^{2}$ Department of Crop Protections, Faculty of Agriculture, University of Khartoum, Shambat, Sudan
}

\begin{abstract}
The study on the two isolates of the fungus Pyrenochaeta terrestris that cause pink root rot disease on onion Allium cepa L., collected from Hudioeba in River Nile state and Islang in Khartoum State in Sudan, was carried out to elucidate the host plants of the fungus isolate.The ecological fitness of the fungus was illustrated by the fact that the pathogen could infect several species of plants (onion, garlic, squash, sorghum, French bean, faba bean, maize, pepper and cucumber), which might commonly constitute the crop sequence in the main onion growing areas. The visual symptoms were observed in onion, garlic and squash, but the other test plants were found to be affected in growth parameters if inoculated with $P$. terrestis without obvious symptoms.
\end{abstract}

Keywords: Pyerenochaeta terrestris, host range, different isolates,

\section{Introduction}

Onion (Allium cepa L.) is a major vegetable crop with great importance. The demand for it is worldwide and is fairly constant throughout the year. It is needed in the daily diet in the Sudan where it is eaten raw as salad or is cooked in a wide variety dishes.

The pink root rot disease is incited by a soil inhabiting fungus (Pyrenochaeta terrestris (Hansen) Gorenz, Walker and Larson) which attacks onion plants from the seedling to maturity stages. The disease is a real threat to onion production all over the world wherever commercial onion is grown. Considerable damage has been caused to onion crop resulting in bulb yield losses ranging from 23 to $76 \%$ (Taubenhaus and Mally, 1921; ElSaggaf, 1997; El Amin, 1999). Onion seed loss of 5.3-32.7 \% was also reported by El Saggaf (1997) and the seeds produced by infected plants were significantly lighter in weight and with low germinability

The first observation of the pink root rot disease in the Sudan was made by Prof. ElHilo at Hudeiba Research Station in early 1960's and in 1982 the causal organism was identified on the basis of cultural characteristics on a specified medium using symptomatic onion roots (Yassin et al, 1982). However, the disease is a serious constraint to onion production in some of the main producing areas of the country such as River Nile, Khartoum, Gezira and Kassala State (El Amin, 1999) as well as in certain parts of Darfur in Western Sudan (Dr. S. M. El Hassan, Personal communication).

The fungus has been found to be associated with onion, multiplier onion, shallot, garlic, leak and chive. It also can infect cantaloupe, carrot, cauliflower, corn, cowpea, cucumber, eggplant, lima bean, millet, vats, peas, peppers, potato, spinach, sugarcane and tomato (Shere and Macnab, 1986). Therefore, the main objective of this study was investigating the host range of this fungus in Sudan.

\section{Materials and Methods}

The original Pyrenochaeta terrestris isolates were provided by Dr. Siddig M. El Hassan, Dept. of Crop Protection Fac. of Agric. Univ. of Khartoum as pure culture of the fungus stored in potato dextrose agar (PDA) in McCartney bottles in the refrigerator.

These fungus isolates were originally isolated from onion samples showing typical pink root disease symptoms collected from Islanj (Khartoum State), and Hudeiba (River Nile State). The two isolates were first re-vitalized by sub culturing in PDA medium under aseptic conditions and incubated for 7 days at $28^{\circ} \mathrm{C}$.

Plants Seeds of cultivars Saggai (red), and Kamlin (yellow), were used and sown in October, 1999 after being sterilized by $\mathrm{NaOC} 1$ in plastic trays containing sterilized sand/clay soil mixture (1:2) and kept in the nursery of Faculty of Agric. Univ. of Khartoum. The seedlings were watered when needed. They were sprayed with Foliar fertilizer, (Khassab' $\left(2 \mathrm{ml} / 1 \mathrm{H}_{2} \mathrm{O}\right)$ after one and 1.5 months from sowing. The seedlings were transplanted in December 1999 to plastic bags (10 seedlings/bag). The soil mixture was inoculated with $P$. terrestris prior to seedling transplanting. The onion seedlings were then maintained in the screen house. 


\section{Inoculum Preparation}

A solid medium was prepared from corn meal sand (CMS) and water (Corn meal sand (95 g sand, $5 \mathrm{~g}$ corn meal $/ 5 \mathrm{ml}$ water). Aliquots of the medium were placed in several flasks and each flask was inoculated with one isolate of $P$. terrestris described above using 3-10 mm inoculum discs from 7-day-old PDA culture per flask. Inoculated flasks were maintained at $27^{\circ} \mathrm{C}$ for $2-3$ weeks. with frequent agitation till the mycelium covered the medium.

\section{Inoculation procedure}

The inoculum prepared above was distributed to the plastic bags and mixed with the top soil at a rate of $2 \%(\mathrm{w} / \mathrm{w})$ and the bags were then irrigated immediately to establish good fungal growth. Three days later, seedlings of onion cultivars Saggai (red), and Kamlin (yellow), were transplanted in the infested bags after trimming of the root system.

\section{Isolation of $P$. terrestris isolates}

After 1.5 months from transplanting in inoculated soil, onion seedlings were up-rooted and washed under running tap water for half an hour. Re-isolation of the fungus was_performed from the symptomatic roots showing pinkish colouration. These roots were cut into pieces $1-2 \mathrm{~cm}$ long, surface sterilized with $0.1 \% \mathrm{HgCl}_{2}$ for 2-3 minutes, rinsed in sterilized distilled water, dried on sterile blotter, and then seeded in Petri dishes with Watson's medium (20 g agar, $3 \mathrm{~g}$ sodium nitrate, $1 \mathrm{~g}$ magnesium sulfate/1 water). Bacterial contamination in the culture was suppressed by adding $0.1 \mathrm{~g} / 1$ streptomycin sulphate. The inoculated plates were incubated at $28^{\circ} \mathrm{C}$ for few days. Pure cultures of different isolates were obtained by transferring pieces of medium $\backslash$ containing advanced growth of colonies from 4-7 day-old culture to PDA) plates. The cultures were incubated at $27^{\circ} \mathrm{C}$ for 7 days. The respective new isolates were named after the area and colour of onion cultivar into which it was passed. These were: Hudieba red (RHu ) and Islanj yellow (YIs). The remaining isolates could not be obtained in pure cultures. The stock cultures were then kept in McCartney bottles containing PDA and stored in a refrigerator at $5^{\circ} \mathrm{C}$ for further investigations.

\section{Host plants}

The test plants included in this experiment were sorghum (Abu 70), maize, squash, cucumber, French bean, faba bean, pepper, garlic and onion.

Onion and pepper were sown in the Nursery of the Faculty of Agriculture, University of Khartoum in August 2000 in plastic trays using sterilized sand/clay soil mixture (1:2). They were sprayed with foliar fertilizer 'Khassab' at a rate of $1 \mathrm{~m} 1 / 1$ at one and 1.5 months of age.

\section{Inoculum preparation for host plants}

A solid culture medium (CMS) was prepared as described above using RHu and YIs isolates. The inoculum discs were transferred from 7-day old culture in PDA and incubated at $27^{\circ} \mathrm{C}$ for $2-3$ weeks.

\section{Inoculation procedure for host plants}

Eighty-one clay pots (18-24 cm diameter) were used in this experiment. The pots were sterilized by dipping in $1 \%$ Formalin. The soil mixture was sterilized as before, distributed equally to the pots and the top soil was inoculated with the above prepared inoculum of RHu and Yls isolates at a rate of 2\% (w/w) and immediately watered. Three days later, seedlings of onion and pepper were transplanted, and seeds of other crops were sown in these infested pots in October 2000. Urea fertilizer was applied at a rate of $100 \mathrm{~kg} / \mathrm{fed} \mathrm{one}$ month and 1.5 months after sowing. Same numbers of non-inoculated plants were maintained as controls. The plants were kept in the screen house for two months and the required data were collected.

\section{Data collected included:-}

- Infection percentage and description of visual symptoms observed.

- Plant height.

- Root length.

- Root fresh weight.

- $\quad$ Shoot fresh weight.

The experiment was arranged in a split plot design with three replications. 


\section{Results}

This experiment was carried out to determine the host range of P. terrestris isolates 'RHu' and 'YIs'. The results in Table 1 demonstrated that, the two isolates were infectious to squash and garlic beside onion, where they caused characteristic symptoms consisting of drying of leaves at the tip (tip burn) and pink discolouration of infected roots. Although, these isolates incited, no obvious symptoms in the other test species under the conditions of the experiment, but they caused considerable reductions of the measured parameters.

\section{Effect on Growth Parameters}

The growth parameters of the different plant species under test were profoundly reduced due to inoculation with either of the two isolates (i.e. RHu and YIs). Generally, there seemed to be no correlation between obvious symptoms of infection and the extent of reduction in growth parameters. In fact, these plants which failed to show detectable symptoms showed as much or even greater reductions in some of the test growth parameters.

The fungus isolates 'RHu' appeared to be more virulent compared to 'Yrs' isolate based on the significant differences between the two isolates in the mean reduction of all growth parameters except the plant height. The interaction between the fungus isolates and test plants was obvious in the root length and number of leaves per plant.

\section{Disease Incidence of test Plants}

The results in Table 2 show the disease incidence of the pink root disease incited by the fungus isolates (RHu, YIs). Significant disease incidence data were recorded in onion, garlic and squash ranging between 29 to $51 \%$ for ' $\mathrm{RHu}$ ' and 19 to 37 for YIs isolates, respectively. There were evident interactions between the fungus isolates and plant species under test. However, presence of visual disease symptoms in the other some plants was not evident.

Table 1. Effect of 'RHu' and YIs' isolates of Phrenochaeta terrestris on growth parameters of nine plant species

\begin{tabular}{|c|c|c|c|c|c|c|c|c|c|c|}
\hline \multirow[t]{2}{*}{ Isolate ${ }^{2}$} & \multicolumn{10}{|c|}{ Peractection of crop parameter } \\
\hline & Syatsh & Oaicn & Garii: & $A b e 70$ & Fabe bear & Mase & Papper & Frasch bean & Cuctuber & Mean \\
\hline RHH & - & + & + & - & - & - & - & - & - & - \\
\hline $\begin{array}{l}\text { Ms } \\
\text { isvlater }\end{array}$ & + & + & + & - & - & - & - & - & - & - \\
\hline \multicolumn{11}{|c|}{ Iretuetiun in root largh } \\
\hline $\mathrm{RH}$ & $35.370^{12}$ & $43.433^{2}$ & $38.143^{32}$ & $24.957^{7+2}$ & $36.370^{12}$ & $33.767^{27}$ & $25.943^{325}$ & $20.007^{72}$ & $26.300^{2 \mathrm{pth}}$ & $31.588^{2}$ \\
\hline $\mathrm{Mls}$ & $29.393^{2=x}$ & $33.050=$ & $26.467=$ & $8.567^{\mathrm{e}}$ & $27.380^{m=}$ & $22.343^{2}=$ & $30.330^{\text {arz }}$ & $30.523^{=e}$ & $22.407^{7 z}$ & $25.607:$ \\
\hline Matx & $32.382^{2}$ & $38.242^{\mathrm{z}}$ & $32.305^{2}$ & $16.762^{\circ}$ & $31.875^{2}$ & $28.055^{2}$ & $28.137+=$ & $25.265^{=}$ & $24.353^{3=}$ & \\
\hline \multicolumn{11}{|c|}{ Soreduction in plant haight } \\
\hline RFfo & $17.830^{2}$ & $860^{2}$ & $26.210^{2}$ & $14.760^{2}$ & $6.673^{3}$ & $5.807^{2}$ & $9.113^{7}$ & $35.793^{2}$ & $20.007^{2}$ & $15.049^{2}$ \\
\hline $\mathrm{His}$ & $24.773^{2}$ & $17.393^{2}$ & $6.760^{2}$ & $9.237^{2}$ & $21320^{2}$ & $20.073^{2}$ & $36.410^{2}$ & $14.097^{=}$ & $14.960^{\mathrm{z}}$ & $19.447^{2}$ \\
\hline Masx & 16. $302^{2}$ & $19.127^{2}$ & $16.485^{=}$ & $11.993^{2}$ & $13.997^{=}$ & $7.133^{2}$ & $22.762^{2}$ & $24.945^{2}$ & $22.483^{2}$ & \\
\hline \multicolumn{11}{|c|}{ Sorduction in foot fresh waight } \\
\hline $\mathrm{RH}$ & $57.980^{2}$ & $40.023^{2}$ & $13.47^{2}$ & $32.207^{2}$ & $18.617^{7}$ & $53.317^{2}$ & $57.000^{2}$ & $32.897^{2}$ & $46.997^{2}$ & $39.163^{2}$ \\
\hline Ys & $14.270^{2}$ & $32.850^{2}$ & $27.373^{2}$ & $11.457^{2}$ & $16.780^{2}$ & $52.433^{\circ}$ & $54.140^{2}$ & $55.510^{2}$ & $15.143^{2}$ & $31.106^{2}$ \\
\hline Mesx & $36.125^{2}$ & $36.437^{2}$ & $20.400^{2}$ & $21.850^{2}$ & $17.698^{2}$ & $52.875^{2}$ & $55.570^{2}$ & $44.203^{2}$ & $31.070^{2}$ & \\
\hline \multicolumn{11}{|c|}{ Greduction in number of lavas } \\
\hline $\mathrm{RH}$ & $27.617^{7 P}$ & $36.74^{2}$ & $8.177^{3 t}$ & $30.533^{2}$ & $31.140^{12}$ & $29.867^{72}$ & $28.01^{72}$ & $7.403^{\mathrm{meg}}$ & $25.63^{27}$ & $24.754^{2}$ \\
\hline $\mathrm{Ms}$ & $6.803^{2}$ & $32.530^{2}=$ & $19.590^{=}$ & $28.193=$ & $12.990^{205}$ & $21.890^{21=}$ & $25.013^{* x}$ & $4.307 \%$ & $20.437^{m}$ & $17.565^{2}$ \\
\hline Mear & $10.407^{\circ 6}$ & $36.638=$ & $13.883^{2}$ & $29.363^{=}$ & $22.035^{20}$ & $24.788^{=5}$ & $26.515^{ \pm=}$ & $5.855^{7}$ & $12.950=$ & \\
\hline \multicolumn{11}{|c|}{ Treduction in shoot frash waight } \\
\hline RHA & $46.303^{2}$ & $33.830^{2}$ & $47.947^{2}$ & $28.480^{2}$ & $12.223^{2}$ & $45.757^{2}$ & $44.537^{2}$ & $36.637^{2}$ & $19.610^{2}$ & $35.041^{2}$ \\
\hline $\mathrm{Ms}$ & $33297^{2}$ & $7.413^{2}$ & $11.173^{2}$ & $43.113^{2}$ & $39.303^{2}$ & $40.060^{2}$ & $49.933^{\circ}$ & $14.073^{2}$ & $34.983^{2}$ & $30.372^{*}$ \\
\hline Maax & $39.800^{2}$ & $20.622^{2}$ & $29.560^{2}$ & $35.767^{2}$ & $25.763^{2}$ & $42.908^{2}$ & $47.235^{\circ}$ & $25.380^{2}$ & $27.297=$ & \\
\hline
\end{tabular}

*isolates:RHuHudeiba isolate passed into Saggai (red).

YIslslanj isolate passed into Kamiln (yellow)

$+=$ With observed symptoms (pink pigmentation of roots and/or tip burn). - = No observed symptoms.

Means followed by the same letter(s) are not significantly different $(\mathrm{P}=0.05)$. 
Host Plants of Pyrenochaeta Terrestris the Causal Agent of Pink Root Rot Disease on Onion...

Table2. Disease incidence (\%) incited by (RHu) and (YIs) isolates of Pyrenochaeta terrestris on different plant species

\begin{tabular}{|l|l|l|c|l|}
\hline \multirow{2}{*}{$\begin{array}{l}\text { Plant } \\
\text { species }\end{array}$} & Fungus isolates* & \multicolumn{3}{l|}{} \\
\cline { 2 - 5 } & YIs & RHu & Control & Mean \\
\hline Squash & $19.280^{\mathrm{d}}$ & $29.453^{\mathrm{c}}$ & $1.280^{\mathrm{e}}$ & $16.671^{\mathrm{c}}$ \\
\hline Onion & $37.2231^{\mathrm{b}}$ & $51.260^{\mathrm{a}}$ & $0.900^{\mathrm{e}}$ & $29.797^{\mathrm{a}}$ \\
\hline Garlic & $29.453^{\mathrm{c}}$ & $36.067^{\mathrm{b}}$ & $0.900^{\mathrm{e}}$ & $22.140^{\mathrm{b}}$ \\
\hline Abu 70 & $0.900^{\mathrm{d}}$ & $2.870^{\mathrm{c}}$ & $0.900^{\mathrm{c}}$ & $1.557^{\mathrm{d}}$ \\
\hline Faba bean & $1.863^{\mathrm{e}}$ & $2.453^{\mathrm{e}}$ & $0.983^{\mathrm{e}}$ & $1.767^{\mathrm{d}}$ \\
\hline Maize & $1.350^{\mathrm{e}}$ & $1.320^{\mathrm{e}}$ & $0.930^{\mathrm{e}}$ & $1.317^{\mathrm{d}}$ \\
\hline Pepper & $1.0097^{\mathrm{e}}$ & $1.670^{\mathrm{e}}$ & $1.180^{\mathrm{e}}$ & $1.232^{\mathrm{d}}$ \\
\hline French & $1.290^{\mathrm{e}}$ & $1.433^{\mathrm{e}}$ & $1.280^{\mathrm{e}}$ & $1.280^{\mathrm{e}}$ \\
\hline Cucumber & $1.280^{\mathrm{e}}$ & $1.280^{\mathrm{e}}$ & $1.070^{\mathrm{c}}$ & \\
\hline Mean & $10.415^{\mathrm{b}}$ & $14.201^{\mathrm{a}}$ & & \\
\hline
\end{tabular}

*Fungus isolates:

YIs: Islanj isolates passed into Kamlin (yellow).

RHu: Hudeiba isolate passed into Saggai (red).

Means followed by the same letter(s) are not significantly different $(\mathrm{P}=0.05)$.

\section{Discussion}

The ecological fitness of the pathogen is enhanced by the fact that many plant species including common vegetable crops, which frequently rotate with onion, are also hosts for P. terrestris. Six of the host plants other than squash, onion and garlic under test exhibited no visual symptoms. This was in contrast with the findings of Thorn-berry and Anderson (1940); Kreutzer (1941); Schneider (1965) and Shere and Macnab (1986), who reported that, these crops had displayed root rot symptoms. One explanation for this disparity could be that the isolates tested might differ in their physiological reactions to these host plants from the ones reported by the above workers. However, considerable effects on roots and above ground parts were observed, particularly in the root growth. Generally, no significant variations seemed to occur between the tested host plants. This may indicate that the infection in these host crops showing no clear symptoms is symptomless. The 'RH\& isolate was invariably the more aggressive compared to 'YIs' isolate except in plant height where the reverse was true. These data are in close accord to those reported by El Amin (1999).

\section{References}

[1] El Amin, I. H. (1999). Investigations on onion pink root disease in Sudan. Ph. D. thesis, University of Khartoum, Sudan

[2] El-Saggaf, S. M. (1997). Studies on the pink root disease of onion Pyrenochaeta terrestris (Hansen) Gornez, walker and larson in Wadi- Hadhramout, Yemen. M. Sc. Thesis, University of Khartoum Sudan.

[3] Kreutzer, W. A. (1941). Host parasite relationship in pink root of Allium cepa and other hosts. Phytopathology 31: 907 915.

[4] Schneider, R. (1965). Identifying the agent of onion pink root, Pyrenochaeta terrestris in Germany. Phytopath. Z. 53: $249-254$.

[5] Shere, A. F. and Macnab, A. A. (1986). Vegetable diseases and their control (Second edition). U. S. A. P: $454-455$.

[6] Taubenhaus, J. J. and Malty, F. W. (1921). Pink root disease of onions and its control in Texas. Texas Agric. Exp. Sta. Bull. 273: 42.

[7] Thornberry, H. H., and Anderson, H. W. (1940). Pink root disease of onions on tomatoes. Plant Dis. Reptr. 24: 383 384.

[8] Yassin, A. M., Babiker, A. G. T., and Ahmed, M. K. (1982). First report of pink root of onion in Sudan (Pyrenochcteta terrestns) Plant Dis. 66: 741 . 